\title{
Severity/Intensity Scale for Adverse Events
}

National Cancer Institute

\section{Source}

National Cancer Institute. Severity/Intensity Scale for Adverse Events. NCI Thesaurus.

Code $C 49705$.

A scale that defines the degree or state of disease existing in a patient as a result of the occurrence of an adverse event. 